\title{
Line Unit of Length
}

National Cancer Institute

\section{Source}

National Cancer Institute. Line Unit of Length. NCI Thesaurus. Code C71221.

A unit of length equal 1/12 inch, approximately 2.1167 millimeters. 